\title{
Формирование контактов MnGa/GaAs для применений в оптоэлектронике и спинтронике
}

\author{
() М.В. Дорохин ${ }^{+}$, Д.А. Павлов*, А.И. Бобров*, Ю.А. Данилов ${ }^{+}$, \\ В.П. Лесников ${ }^{+}$, Б.Н. Звонков ${ }^{+}$, А.В. Здоровейщев ${ }^{+}$, А.В. Кудрин*, \\ П.Б. Демина ${ }^{+}$, Ю.В. Усов*, Д.Е. Николичев*, Р.Н. Крюков*, С.Ю. Зубков* \\ + Научно-исследовательский физико-технический институт \\ Нижегородского государственного университета им. Н.И. Лобачевского, \\ 603950 Нижний Новгород, Россия \\ * Нижегородский государственный университет им. Н.И. Лобачевского (фризический фракультет), \\ 603950 Нижний Новгород, Россия \\ E-mail: dorokhin@nifti.unn.ru
}

(Получена 27 апреля 2016 г. Принята к печати 10 мая 2016 г.)

Исследованы кристаллическая структура, состав, магнитные и электротранспортные свойств слоев $\mathrm{Mn}_{x} \mathrm{Ga}_{y}$, осажденных на поверхность $\mathrm{GaAs}$ методами импульсного лазерного осаждения в потоке водорода, импульсного лазерного осаждения в вакууме и электронно-лучевого испарения в высоком вакууме. Показано, что особенности каждого из методов оказывают влияние на состав и кристаллическую структуру формируемых слоев, на степень резкости и кристаллического совершенства гетерограницы. Состав и кристаллическая структура, предположительно, обусловливают модификацию ферромагнитных свойств. Дефекты гетерограницы оказывают влияние на свойства диодной структуры $\mathrm{Mn}_{x} \mathrm{Ga}_{y} / \mathrm{GaAs}$, в частности на высоту потенциального барьера диода Шоттки.

\section{1. Введение}

Создание систем металл/полупроводник для приборов спинтроники и оптоэлектроники требует формирования совершенной границы раздела, содержащей минимальное количество дефектов. Известно, что однородность и степень кристаллического упорядочения ферромагнитных и полупроводниковых слоев вблизи гетерограницы оказывают существенное влияние на характеристики приборных структур [1-3]. В частности, близкая к идеальной граница раздела ферромагнетика и полупроводника обеспечивает высокую эффективность инжекции спин-поляризованных носителей из ферромагнитного металла в неферромагнитный полупроводник [1-3]. Материалы, которые наиболее часто используются для создания таких систем, как правило, не образуют совершенной гетерограницы с основными полупроводниками, такими как $\mathrm{Si}$, GaAs (например, контакты Au/GaAs, Ni/GaAs формируются с образованием дефектов различной природы) [4]. В то же время существуют новые материалы, параметры которых обеспечивают возможность эпитаксиального выращивания на поверхности $\mathrm{Si}$, GaAs. К таким материалам относятся соединения галлида марганца $\left(\mathrm{Mn}_{x} \mathrm{Ga}_{y}\right)$ [5-7]. В отличие от известных ферромагнитных материалов, эпитаксиальное выращивание которых на поверхности полупроводника требует специальных технологических условий $[8,9]$, для $\mathrm{Mn}_{x} \mathrm{Ga}_{y}$ была продемонстрирована возможность формирования кристаллически совершенной эпитаксиальной структуры на GaAs, в том числе, с применением технологии импульсного лазерного осаждения, не обеспечивающей „стандартных“ для технологии магнитных гетероструктур требований выращивания в сверхвысоком вакууме и in situ контроля процес- са роста [7]. Возможности варьирования технологии осаждения эпитаксиальных слоев $\mathrm{Mn}_{x} \mathrm{Ga}_{y}$ значительно упрощают создание приборов, а также расширяют возможный диапазон применений галлида марганца для формирования структур спинтроники на основе GaAs. В настоящей работе выполнено сравнительное исследование кристаллической структуры, электрических и магнитных свойств эпитаксиальных слоев $\mathrm{Mn}_{x} \mathrm{Ga}_{y} / \mathrm{GaAs}$, полученных с применением различных технологических методик: импульсного лазерного осаждения (ИЛО) в атмосфере водорода [7], импульсного лазерного осаждения в вакууме [10] и электронно-лучевого испарения (ЭЛИ) в высоком вакууме.

\section{2. Методика эксперимента}

Структуры для исследований были изготовлены двухстадийным ростовым методом. На первой стадии эксперимента методом МОС-гидридной эпитаксии формировалась излучающая структура на подложке $n$-GaAs (100), которая представляла собой $n$-GaAs буферный слой толщиной 300 нм и InGaAs квантовую яму (10 нм), зарощенную 30 нм слоем $i$-GaAs. Температура осаждения составила $600^{\circ} \mathrm{C}$. На второй стадии процесса на поверхности структур осаждался слой галлида марганца $\mathrm{Mn}_{x} \mathrm{Ga}_{y}$, таким образом формировались диоды с контактом $\mathrm{Mn}_{x} \mathrm{Ga}_{y} / \mathrm{GaAs}$, которые аналогичны диодам с барьером Шоттки. В работе использованы три различных технологии формирования $\mathrm{Mn}_{x} \mathrm{Ga}_{y}$, обозначим исследованные структуры как структуры $A, B$ и $C$. В диодах серии $A$ слой галлида марганца сформирован методом ИЛО в атмосфере водорода. Осаждение осуществлялось путем распыления твердотельной мишени $\mathrm{MnGa}_{3}$ импульсным 
Параметры слоев $\mathrm{Mn}_{x} \mathrm{Ga}_{y} / \mathrm{GaAs}$, сформированных различными методами, а также диодов на их основе

\begin{tabular}{|c|c|c|c|c|c|}
\hline Образец & Метод получения & $\begin{array}{c}\text { Кристаллическая } \\
\text { структура }\end{array}$ & $x_{\mathrm{Mn}}, \mathrm{aT} \%$ & $y_{\mathrm{Ga}}, \mathrm{aT} \%$ & $\varphi_{0}$, эB \\
\hline$A$ & ИЛО в атмосфере $\mathrm{H}_{2}$ & $\begin{array}{l}\text { Двухфазный } \\
\text { монокристалл }\end{array}$ & --- & --- & $0.9 \pm 0.05$ \\
\hline$B$ & ИЛО в вакууме & $\begin{array}{l}\text { Дефектный } \\
\text { монокристалл }\end{array}$ & $24.7 \pm 0.5$ & $75.3 \pm 0.5$ & --- \\
\hline$C$ & ЭЛИ в вакууме & Аморфный & $32.9 \pm 0.5$ & $67.1 \pm 0.5$ & $0.66 \pm 0.05$ \\
\hline
\end{tabular}

лазером (Nd:YAG), работающим в режиме модулированной добротности. Распыление выполнялось в потоке водорода непосредственно после формирования полупроводниковой структуры в реакторе МОСГЭ [7,11]. В процессе распыления частицы осаждаемого вещества захватывались газом-носителем $\left(\mathrm{H}_{2}\right)$ и осаждались на поверхности полупроводниковой структуры.

В диодах серии $B$ слой галлида марганца сформирован методом ИЛО в вакууме. Для этого сформированная полупроводниковая структура перемещалась в установку импульсного лазерного осаждения, при этом подвергаясь воздействию воздушной среды. В реакторе ИЛО образец предварительно отжигался при $570^{\circ} \mathrm{C}$, затем на поверхности формировался слой $\mathrm{Mn}_{x} \mathrm{Ga}_{y}$ методом импульсного лазерного осаждения в высоком вакууме $[10,12]$.

В диодах серии $C$ слой галлида марганца формировался методом ЭЛИ в высоком вакууме. Аналогично случаю серии $B$ полупроводниковая структура перемещалась с нетехнологическим экспонированием в воздушной среде в высоковакуумную установку электронно-лучевого испарения. В указанной установке образец также подвергался отжигу при температуpe $500^{\circ} \mathrm{C}$, затем на поверхности формировался слой $\mathrm{Mn}_{x} \mathrm{Ga}_{y}$ методом электронно-лучевого испарения твердотельной мишени.

Температура осаждения $\mathrm{Mn}_{x} \mathrm{Ga}_{y}$ во всех случаях составляла $300^{\circ} \mathrm{C}$, толщина слоя 20 нм. Для осаждения во всех случаях использовалась мишень твердого раствора галлида марганца с приблизительным составом $\mathrm{MnGa}_{3}$.

В работе приведены результаты исследований кристаллической структуры поперечного среза образцов, выполненных с помощью просвечивающего электронного микроскопа JEM-2100F с энергодисперсионным детектором Х-Мах. Изучен состав слоев галлида марганца методом рентгеновской фотоэлектронной спектроскопии (РФЭС), а также проведены исследования вольт-амперных характеристик диодов и магнитополевых зависимостей намагниченности.

Исследования методом РФЭС проводились на комплексе Multiprobe RM (Omicron Nanotechnology $\mathrm{GmbH}$, Германия). Для возбуждения фотоэмиссии использовались $\operatorname{Mg} K_{\alpha}$-излучение $\left(h v=1253.6\right.$ эВ) и $\mathrm{Al} K_{\alpha}$-излучение $(h v=1486.6$ эВ). Диаметр области анализа составлял 1.5 мм. Послойное профилирование осуществлялось травлением ионами $\mathrm{Ar}^{+}$, имеющими энергию, равную 1 кэВ, при проведении этой процедуры давление в камере составляло $4 \cdot 10^{-6}$ мбар. Угол между осью ионной пушки и нормалью к поверхности образца составлял $45^{\circ}$. Спектр вторичных электронов измерялся с использованием полусферического (с радиусом $125 \mathrm{Mм}$ ) анализатора энергий ЕА-125. Предельная обнаруживаемая концентрация элементов определялась соотношением сигнал/шум на фотоэлектронных спектрах и составляла $0.5 \mathrm{aT} \%$. Для определения концентрации химических элементов производилась запись ФЭ-линий: $\mathrm{O} 1 s, \mathrm{C} 1 s, \mathrm{Ga} 2 p_{3 / 2}, \mathrm{Mn} 2 p_{3 / 2}$. Спектры снимались при энергии пропускания анализатора 50 эВ и дискретизации по энергии 0.2 эВ/шаг.

Исследования намагниченности выполнялись с применением калиброванного магнетометра переменного градиента поля [13]. Измерения проводились при приложении магнитного поля перпендикулярно поверхности структуры (перпендикулярная геометрия) и при приложении магнитного поля вдоль поверхности (продольная геометрия). Для исследования ВАХ были сформированы диоды, для этого на последней стадии технологического процесса формировались мезаструктуры с контактами диаметром 500 мкм с применением методов фотолитографии и травления. Параметры образцов для исследований приведены в таблице.

\section{3. Результаты и обсуждение}

Электронно-микроскопические изображения поперечного среза приповерхностных слоев структур $A, B$ и $C$ показаны на рис. $1, a, 1, b$ и $1, c$ соответственно. В образцах серии $A$ и $B$ слои галлида марганца, сформированные методами импульсного лазерного осаждения, имеют упорядоченную кристаллическую структуру, их кристаллографическая ориентация задается подложкой $\mathrm{GaAs}(100)$. Для структуры $A$ (рис. $1, a)$ наблюдаются две атомно-упорядоченные фазы $\mathrm{Mn}_{x} \mathrm{Ga}_{y}$ (отмеченные цифрами 1 и 2). Размеры каждой фазы составляют $\sim 1-2$ мкм, а их соотношение примерно равно 50/50\%. Вероятно, указанные фазы соответствуют двум различным кристаллографическим ориентациям кристаллитов галлида марганца, причем ориентация каждой из фаз когерентна с подложкой. Установление механизма образования двух фаз $\mathrm{Mn}_{x} \mathrm{Ga}_{y}$ на одной подложке затруднительно, однако можно предположить, что каждая фаза соответствует галлиду марганца с несколько 

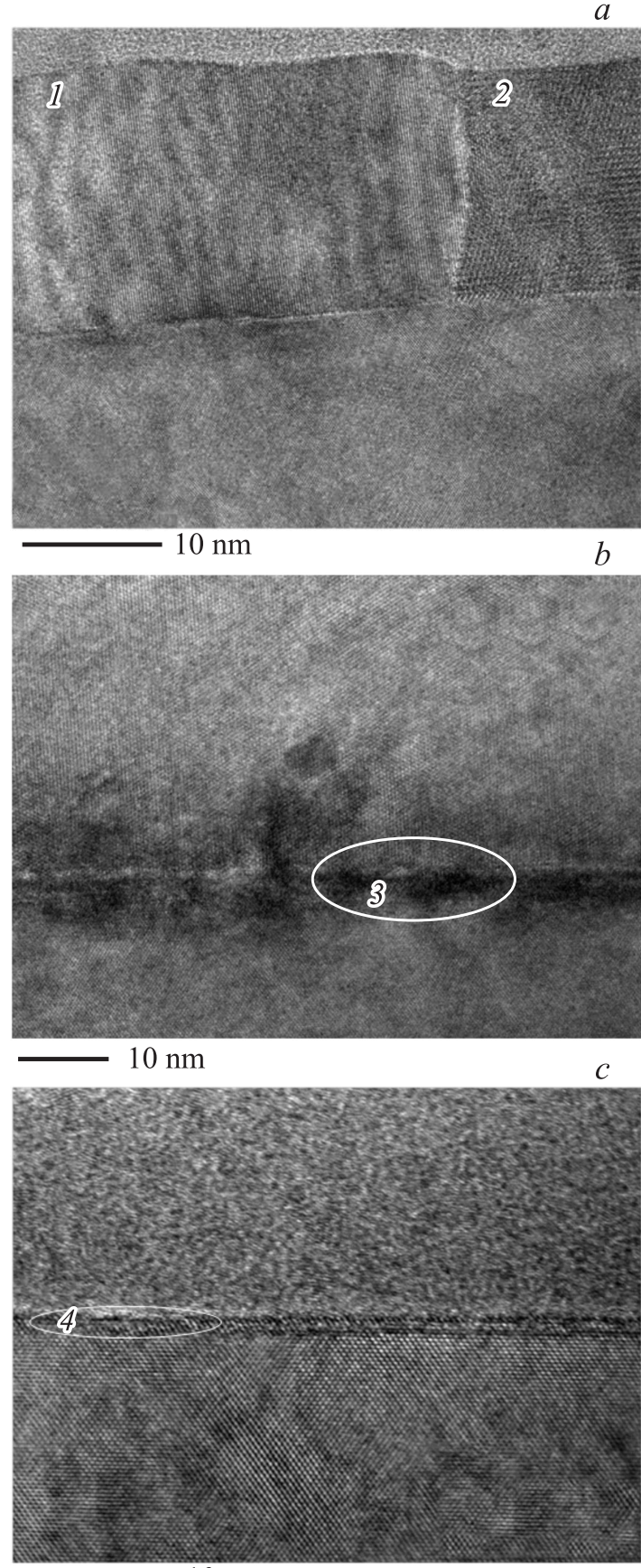

$10 \mathrm{~nm}$

Рис. 1. Изображение высокого разрешения приповерхностных слоев и границы раздела поперечного среза структуры $\mathrm{Mn}_{x} \mathrm{Ga}_{y} / \mathrm{GaAs}$, сформированной методом $A-$ ИЛО в атмосфере водорода. Отмечены области 1 и 2 с разной кристаллографической ориентацией $(a)$; методом $B-$ ИЛО в вакууме. Овалом выделена область неупорядоченной атомной структуры $(b)$ и методом $C$ - электронно-лучевым испарением в вакууме $(c)$.

отличающимся составом, что может быть обусловлено некоторым отклонением состава исходной мишени от $\mathrm{MnGa}_{3}$ (таким образом, суммарный состав элементов двух фаз отличается от $\mathrm{MnGa}_{3}$ ).
Для структуры $B$ (рис. $1, b)$ второй фазы галлида марганца не зарегистрировано (электронно-микроскопическое изображение слоя подобно изображению фазы 1 на рис. $1, a)$. В то же время сам слой неоднороден по толщине (высота неровностей поверхности сопоставима с толщиной слоя) и содержит большое количество дефектов. Также на снимке поперечного среза в области GaAs непосредственно вблизи границы со слоем $\mathrm{Mn}_{x} \mathrm{Ga}_{y}$ регистрируются темные контрастные области c неупорядоченной структурой, которые связываются с дефектами, вносимыми в полупроводниковые слои при нанесении галлида марганца. На рисунке овалом 3 выделена одна из таких областей. Отметим, что для структуры $A$ темных областей в приповерхностной области полупроводника не зарегистрировано (рис. 1, $a$ ).

В отличие от структур, полученных методами ИЛО, для структуры серии $C$ (электронно-лучевое испарение) зарегистрирована неупорядоченная кристаллическая структура верхнего слоя $\mathrm{Mn}_{x} \mathrm{Ga}_{y}$ (рис. 1,c). Слой $\mathrm{Mn}_{x} \mathrm{Ga}_{y}$ является однородным по толщине, а на границе $\mathrm{Mn}_{x} \mathrm{Ga}_{y} / \mathrm{GaAs}$ наблюдается темная контрастная полоса 4 , которая, предположительно, соответствует области диффузионного перемешивания $\mathrm{Mn}_{x} \mathrm{Ga}_{y}$ и GaAs. Таким образом, эпитаксиальный рост галлида марганца на GaAs (100) при формировании методом электронно-лучевого испарения не осуществляется для выбранной температуры осаждения $\left(300^{\circ} \mathrm{C}\right)$.

На рис. 2, $a$ и $b$ представлены магнитополевые зависимости намагниченности исследованных структур, измеренные в перпендикулярной и продольной геометриях соответственно. Получено, что все сформированные слои галлида марганца являются ферромагнетиками при комнатной температуре. Обнаружено, что ферромагнитные свойства существенно зависят от условий осаждения слоев.

Для слоев, сформированных методами $A$ и $B$, при измерениях в продольной геометрии магнитополевая зависимость намагниченности представляет собой петлю гистерезиса, при этом значительно отличаются величины коэрцитивного поля (рис. 2, $a$, кривые 1 и 2 соответственно). При измерениях в перпендикулярной геометрии для слоев $A$ получена зависимость намагниченности с нулевым коэрцитивным полем (петля гистерезиса отсутствует). Это свидетельствует о положении оси легкого намагничивания в плоскости структуры. Для слоев $B$ петля гистерезиса зарегистрирована для обеих измерительных геометрий, т.е. ось легкого намагничивания имеет как плоскостную, так и перпендикулярную компоненты (рис. 2, кривая 2). Возможно, это связано с относительно высокой степенью разупорядочения кристаллитов пленки $\mathrm{Mn}_{x} \mathrm{Ga}_{y}$.

Для структур $C$ параметры намагниченности существенно отличаются от описанных выше двух случаев (рис. 2, кривая 3). Для обоих направлений магнитного поля относительно плоскости замыкание петли гистерезиса наблюдается в максимальном магнитном поле из рассмотренного диапазона. Замыкание петли в 

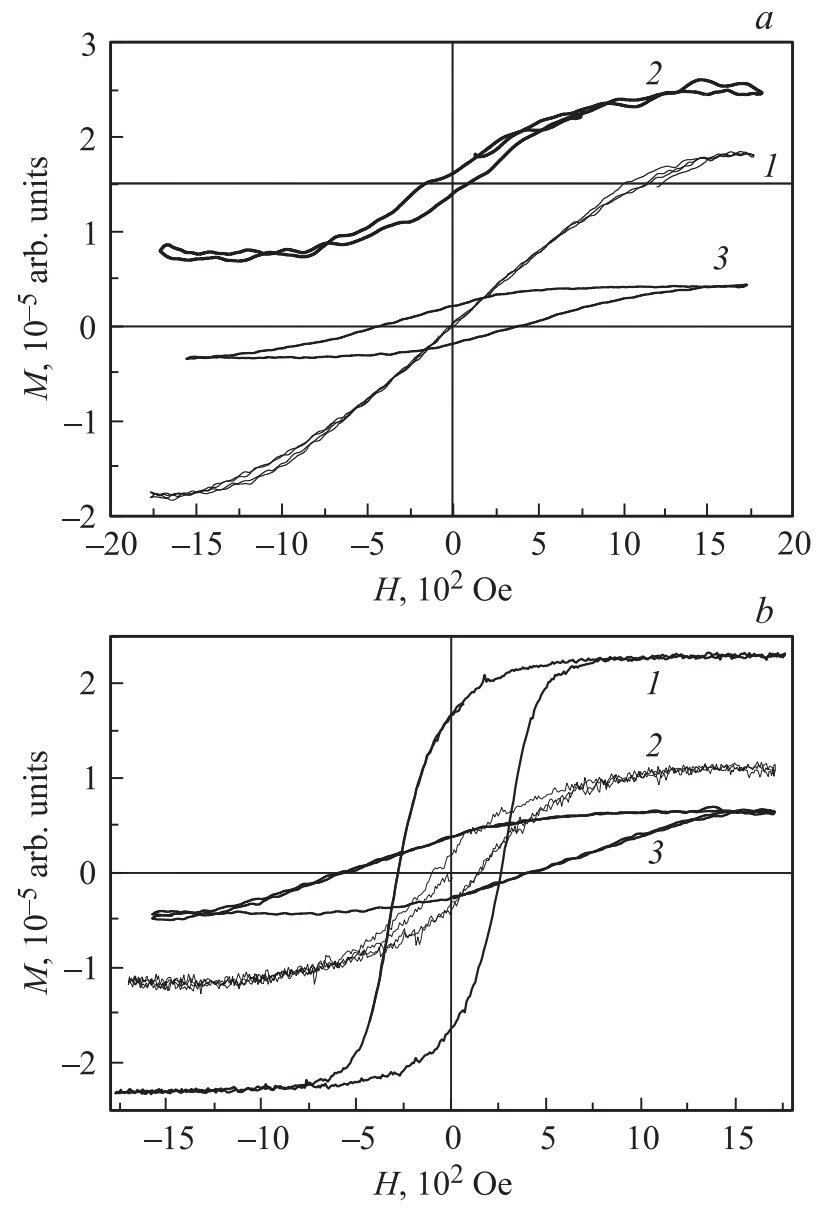

Рис. 2. Магнитополевые зависимости намагниченности слоев галлида марганца, сформированных методом ИЛО в атмосфере водорода (кривая 1), ИЛО в вакууме (кривая 2), электронно-лучевого испарения в вакууме (кривая 3). $a$ - магнитное поле направлено перпендикулярно поверхности, кривая 2 смещена вверх по оси ординат для ясности рисунка; $b-$ магнитное поле направлено в плоскости структуры. Измерения выполнены при температуре $300 \mathrm{~K}$ на магнетометре переменного градиента поля.

максимальном поле не позволяет сделать вывод о насыщении намагниченности как в перпендикулярной, так и в продольной геометрии. При этом наличие сигнала намагниченности, так же как и регистрация петли гистерезиса на зависимости $M(H)$, свидетельствует о том, что частичное намагничивание слоев имеет место. Таким образом, магнитные свойства слоев $\mathrm{Mn}_{x} \mathrm{Ga}_{y}$, сформированных разными методами, существенно различаются.

Вольт-амперные характеристики диодов с контактом $\mathrm{Mn}_{x} \mathrm{Ga}_{y}$ для всех серий структур представлены на рис. 3. Полученные ВАХ являются несимметричными и выпрямляющими. Прямое смещение соответствует положительному относительно базы потенциалу на $\mathrm{Mn}_{x} \mathrm{Ga}_{y}$. Отметим качественное различие BAX структур с контактами, сформированными различными методами: ИЛО в атмосфере водорода (кривая 1); ИЛО в вакууме (кривая 2) и электронно-лучевого испарения (кривая 3).
В первом случае (структуры $A$ ) вид ВАХ наиболее близко соответствует характеристикам диода с барьером Шоттки, а величина обратных токов не превышает 2 нА. Для диодов серии $B$ величина обратных токов диода достигает величины $1 \mathrm{~mA}$ при $U_{d}=-2 \mathrm{~B}$, а при напряжениях $( \pm 0.2 \mathrm{~B})$ ВАХ симметрична относительно оси ординат. Для диодов серии $C$ вид ВАХ подобен ВАХ диода серии $A$, но величина обратного тока в этом случае выше и составляет $\sim 10^{-5} \mathrm{~A}$ при $U_{d}=-2 \mathrm{~B}$. Отметим более высокие значения прямого тока при одинаковых значениях напряжения для структуры $C$ по сравнению с диодом серии $A$. Различия между характеристиками диодов серии $A$ и $C$ связаны с отличием в высоте потенциального барьера диодов Шоттки на основе указанных структур. Экспериментальные результаты позволяют выполнить оценку высоты потенциального барьера $\left(\varphi_{b}\right)$. Согласно теории [14], прямая ветвь ВАХ может быть описана уравнением

$$
I_{d}=I_{S}\left(\exp \left(\frac{|e| U_{d}}{k k T}\right)-1\right),
$$

где $e-$ заряд электрона, $k-$ постоянная Больцмана, $T$ - температура, $n$ - так называемый коэффициент неидеальности, $I_{S}$ - ток насыщения, определяемый по формуле

$$
I_{S}=A^{*} T^{2}\left(\exp \left(-\frac{|e| \varphi_{b}}{k T}\right)\right),
$$

где $A^{*}$ - постоянная Ричардсона, для GaAs paвная $8.16 \mathrm{~A} \cdot \mathrm{cm}^{-2} \mathrm{~K}^{-2}, \varphi_{b}-$ высота потенциального барьера.

Экстраполяция ВАХ, построенной в полулогарифмических координатах, в точку $U_{d}=0$ позволяет рассчитать значения $\varphi_{b}$. Результаты расчета представлены в таблице. Для диода серии $A$ значение $\varphi_{b}=0.9 \pm 0.05$ эВ, что сопоставимо со значением высоты барьера Шотт-

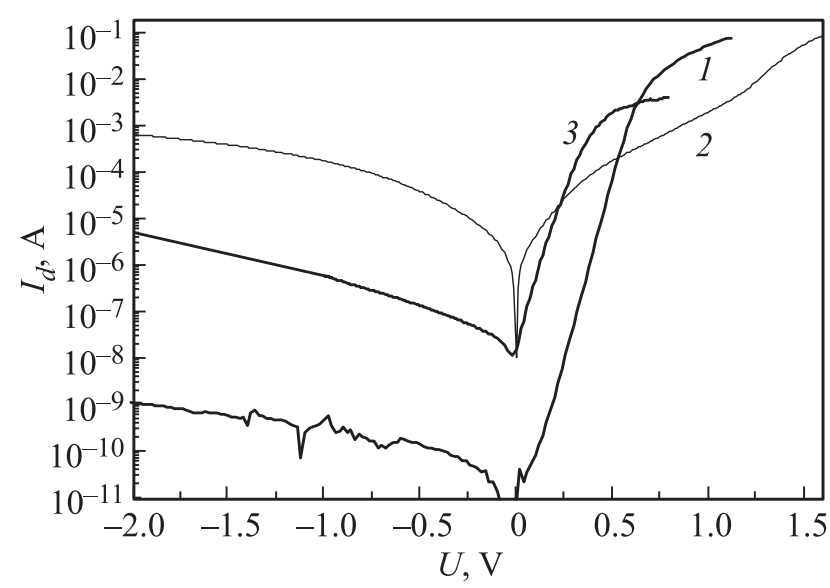

Рис. 3. Вольт-амперные характеристики диодов на основе структур $\mathrm{Mn}_{x} \mathrm{Ga}_{y} / n$-GaAs, измеренные при температуре $300 \mathrm{~K}$, для структур со слоем $\mathrm{Mn}_{x} \mathrm{Ga}_{y}$, сформированным методом ИЛО в атмосфере водорода (кривая 1), ИЛО в вакууме (кривая 2), электронно-лучевого испарения в вакууме (кривая 3 ). 
ки $\mathrm{Au} / \mathrm{GaAs}[15]$, который можно считать „стандартным“ видом барьера в микроэлектронике на основе GaAs. Для диода серии $C$ получено меньшее значение $\varphi_{b}=0.66 \pm 0.05$ эВ. Более низкое значение высоты потенциального барьера обусловливает более высокие значения прямого и обратного тока диодов. Для диода серии $B$ вольт-амперная характеристика не может быть описана формулой (1), что, вероятно, обусловлено токами утечки с участием дефектных центров. Характерным признаком вклада утечек в ток диода с барьером Шоттки являются близкие значения прямых и обратных токов на вольт-амперной характеристике в диапазоне напряжений $( \pm 0.2 \mathrm{~B})$.

Результаты исследований вольт-амперных характеристик мы связываем с особенностями формирования гетерограницы $\mathrm{Mn}_{x} \mathrm{Ga}_{y} / \mathrm{GaAs}$ при осаждении ферромагнитных слоев. Согласно данным просвечивающей электронной микроскопии, наиболее совершенная гетерограница формируется в случае структур серии $A$ (рис. $1, a)$. Это соответствует наибольшему значению высоты потенциального барьера и наименьшему значению обратных токов. На изображении высокого разрешения поперечного среза структуры серии $B$ (рис. $1, b)$ регистрируются дефектные области на границе ферромагнетика и полупроводника (отмеченные овалом). Вероятно, указанные области обусловливают наличие токов утечки в диодах серии $B$. Вид ВАХ диодов серии $C$ может быть обусловлен более низким значением высоты потенциального барьера по сравнению с диодами $A$. Последнее связывается с образованием переходного слоя в полупроводнике вблизи границы $\mathrm{Mn}_{x} \mathrm{Ga}_{y} / \mathrm{GaAs}$ (область 4 на рис. $1, c$ ).

Перейдем к обсуждению результатов исследований. Полученные в работе закономерности обусловлены особенностями формирования границы раздела и кристаллической структуры $\mathrm{Mn}_{x} \mathrm{Ga}_{y} / \mathrm{GaAs}$ для разных методов осаждения. Так, отличительной особенностью метода ИЛО в атмосфере водорода $(A)$ является то, что поток частиц лазерной плазмы направляется в сторону подложки газом-носителем, проходящим через плазменное облако и захватывающим преимущественно легкие частицы распыляемого материала, имеющие тепловые скорости. Тяжелые многоатомные частицы материала, вносящие дефекты в приповерхностный слой, осаждаются на стенках реактора. Таким образом, формируется эпитаксиальная структура со сравнительно гладкой поверхностью [7,11].

В случае метода ИЛО в вакууме $(B)$ в сторону подложки направляется поток ионов и атомов, имеющих кинетическую энергию до $0.3-0.5$ кэВ, а также поток крупных частиц, вносящих нарушения в кристаллическую структуру подложки. Большая дисперсия размеров осаждаемых частиц обусловливает сравнительно высокую неоднородность по толщине слоев.

Отсутствие эпитаксиального роста в случае использования метода электронно-лучевого испарения $(C)$ мы связываем с нарушением стехиометрии $\mathrm{MnGa}_{3}$ при испарении мишени электронным пучком. Данное предполо- жение подтверждается исследованиями состава методом РФЭС, результаты которого представлены в таблице. Для структур $B$, полученных методом импульсного лазерного осаждения, состав слоев ( 24.7 ат\% Mn и $\sim 75.3$ ат\% Ga) приблизительно соответствует составу мишени. Сохранение стехиометрии в методах ИЛО связано с тем, что лазерная плазма преимущественно состоит из многоатомных частиц. При осаждении на поверхности не происходит разложения молекул галлида марганца, поэтому формируется слой с составом, близким к составу мишени. Предположительно, в отличие от ИЛО, в методе электронно-лучевого испарения из мишени галлида марганца испаряется атомарный поток атомов $\mathrm{Mn}$ и $\mathrm{Ga}$, который осаждается на подложку, вступает в реакцию с атомами Ga и As приповерхностного полупроводникового слоя. В этом случае состав слоя $\mathrm{Mn}_{x} \mathrm{Ga}_{y}$ определяется термодинамическими условиями системы пар/подложка, а также реакциями атомов $\mathrm{Mn}$ на поверхности (с атомами Ga из газообразной фазы) и в объеме (с атомами Ga и As) и при этом не соответствует составу мишени. Согласно данным РФЭС (см. таблицу), состав слоя в данном случае соответствует $(\sim 32.9$ ат\% Mn и $\sim 67.1$ ат.\% Ga). Можно предположить, что для слоев галлида марганца с указанным составом не выполняются эпитаксиальные соотношения, поэтому на поверхности формируется аморфная пленка. Отметим, что наличие реакции атомов $\mathrm{Mn}$ с атомами полупроводникового слоя косвенно подтверждается результатами просвечивающей электронной микроскопии (наличие темной полосы на границе $\mathrm{Mn}_{x} \mathrm{Ga}_{y} / \mathrm{GaAs}$, показанное на рис. 1,c). Наличие переходного слоя GaAs:Mn в структуре $\mathrm{Mn}_{x} \mathrm{Ga}_{y} / \mathrm{GaAs}$ приводит к понижению барьера Шоттки, что согласуется с результатами исследований вольт-амперных характеристик структур (см. таблицу).

Таким образом, в работе выполнено исследование кристаллической структуры, состава, магнитных и электротранспортных свойств слоев $\mathrm{Mn}_{x} \mathrm{Ga}_{y}$, осажденных на поверхность GaAs методами импульсного лазерного осаждения в потоке водорода, в вакууме и электронно-лучевого испарения. Показано, что особенности каждого из методов оказывают влияние на состав и кристаллическую структуру формируемых слоев, на степень резкости и кристаллического совершенства гетерограницы. Состав и кристаллическая структура, предположительно, обусловливают модификацию ферромагнитных свойств. Дефекты гетерограницы оказывают влияние на свойства диодной структуры $\mathrm{Mn}_{x} \mathrm{Ga}_{y} / \mathrm{GaAs}$, в частности на высоту потенциального барьера диода Шоттки.

Работа выполнена в рамках реализации государственного задания (проекты № 8.1054.2014/K, № 3.285.2014/K, № 3423) Министерства образования и науки России, при поддержке РФФИ (гранты № 15-02-07824_a, 15-38-20642мол_а_вед и 16-07-01102_a), а также при поддержке гранта Президента РФ (МК-8221.2016.2). 


\section{Список литературы}

[1] Concepts in spin electronics, ed. by S. Maekawa (N. Y, Oxford University Press, 2006).

[2] Y. Xu, D.D. Awschalom, J. Nitta. Handbook of Spintronics (Springer Reference, 2016),

[3] P. Barate, S. Liang, T.T. Zhang, J. Frougier, M. Vidal, P. Renucci, X. Devaux, B. Xu, H.Jaffrés, J.M. George, X. Marie, M. Hehn, S. Mangin, Y. Zheng, T. Amand, B. Tao, X.F. Han, Z. Wang, Y. Lu. Appl. Phys. Lett., 105, 012404 (2014).

[4] L.J. Brillison, R.S. Bauer, R.Z. Bachrach, G. Hansson. Phys. Rev. B, 23, 6204 (1981).

[5] C. Adelmann, J.L. Hilton, B.D. Schultz, S. McKernan, C.J. Palmstrom, X. Lou, H.-S. Chiang, P.A. Crowell. Appl. Phys. Lett., 89, 112511 (2006).

[6] A.W. Arins, H.F. Jurca, J. Zarpellon, Z.E. Fabrim, P.F.P. Fichtner, J. Varalda, W.H. Schreiner, D.H. Mosca. J. Magnetism Magn. Mater., 381, 83 (2015).

[7] М.В. Дорохин, Д.А. Павлов, А.И. Бобров, Ю.А. Данилов, П.Б. Демина, Б.Н. Звонков, А.В. Здоровейщев, А.В. Кудрин, Н.В. Малехонова, Е.И. Малышева. ФТТ, 56 (10), 2062 (2014).

[8] E. Schuster, R.A. Brand, F. Stromberg, F.-Y. Lo, A. Ludwig, D. Reuter, A.D. Wieck, S. Hövel, N.C. Gerhardt, M.R. Hofmann, H. Wende, W. Keune. J. Appl. Phys., 108, 063902 , (2010).

[9] A. Sinsarp, T. Manago, F. Takano, H. Akinaga. J. Supercond. Nov. Magn., 20, 405 (2007).

[10] E.S. Demidov, E.D. Pavlova, A.I. Bobrov. JETP, Lett., 96 (11), 706 (2013).

[11] Б.Н. Звонков, О.В. Вихрова, Ю.А. Данилов, Е.С. Демидов, П.Б. Демина, М.В. Дорохин, Ю.Н. Дроздов, В.В. Подольский, М.В. Сапожников. Оптич. журн., 75 (6), 56 (2008).

[12] В.В. Подольский, В.П. Лесников, Е.С. Демидов, Д.Е. Николичев, В.Г. Бешенков, С.Н. Гусев, С.Ю. Зубков, С.А. Левчук, М.В. Сапожников. Поверхность. Рентгеновские, синхротронные и нейтронные исследования, (5), 10 (2010).

[13] P.J. Flanders. J. Appl. Phys., 63, 3940 (1988).

[14] Э.Х. Родерик. Контакты металл-полупроводник (М., Радио и связь. 1982).

[15] М.В. Дорохин, П.Б. Демина, Н.В. Байдусь, Ю.А. Данилов, Б.Н. Звонков, М.М. Прокофьева. Поверхность. Рентгеновские, синхротронные и нейтронные исследования, (5), 34 (2010).

Редактор Г.А. Оганесян

\section{Fabrication of $\mathrm{MnGa} / \mathrm{GaAs}$ for the optoelectronics and spintronics applications}

M.V. Dorokhin+ D. Pavlov* A.I. Bobrov*, Yu.A. Danilov ${ }^{+}$, V.P. Lesnikov ${ }^{+}$, B.N. Zvonkov ${ }^{+}$, A.V. Zdoroveyshchev ${ }^{+}$, A.V. Kudrin*, P.B. Demina ${ }^{+}$, Yu.V. Usov*, D.E. Nikolichev*, R.N. Kryukov*, S.Yu. Zubkov*

+ Physicotechnical Research Institute of Lobachevsky State University of Nizhny Novgorod, 603950 Nizhny Novgorod, Russia

* Physical Department of Lobachevsky State University of Nizhny Novgorod, 603950 Nizhny Novgorod, Russia

Abstract We report on the investigation of the crystal structure, composition, magnetic and transport properties of $\mathrm{Mn}_{x} \mathrm{Ga}_{y}$ layers deposited on GaAs by means of several techniques: the pulsed laser deposition in vacuum and in hydrogen atmosphere, electron beam evaporation in vacuum. It has been shown that the peculiarities of each of the technique applied affect the composition, crystalline structure, interface abruptness and interface crystalline quality of the structures. The composition and crystalline structure, in turn, modify the ferromagnetic properties whereas interface defects supposedly influence the $\mathrm{Mn}_{x} \mathrm{Ga}_{y} / \mathrm{GaAs}$ diode structure properties, in particular - the potential Schottky barrier height. 